\title{
As ONGs e a Política no Brasil: Presença de Novos Atores
}

\author{
Céli Regina Jardim Pinto
}

oucos temas têm estado tão presentes na atual discussão sobre go-
vernabilidade e democratização quanto o da participação da sociedade civil na qualidade de parceira do Estado na condução de políticas públicas, ou mesmo como substituta deste, em áreas específicas, mormente nas que devem dar conta das políticas sociais.

Na América Latina e, especialmente, no Brasil, esta questão toma contornos particulares, pois até 25 anos atrás era praticamente consenso entre os estudiosos da política a idéia de que os países da região sofriam os efeitos de suas frágeis sociedades civis. Juntava-se a isto a percepção de que nessas áreas a cidadania era uma noção muito distante do cotidiano das populações. Duas razões substantivas colaboravam para tais consensos, a primeira refere-se à própria fragilidade ou quase ausência de sociedade civil na maioria dos países latino-americanos ao longo do século XX. Partes significativas das populações da região viviam, e em alguns países ainda vivem, em áreas rurais e abaixo da linha de pobreza. As cidades começavam a tornar-se metrópoles, muito mais pela imigração de populações em busca do trabalho do que por qualquer outra característica, portanto, havia muito pouca organização a ser analisada. Mas há uma segunda razão que impediu, até muito pouco tempo, os estudiosos de focarem suas preocupações nas sociedades civis latino-americanas como capazes de exercerem papéis relevantes na região: trata-se da centralidade que o Estado ocupou na re-

DADOS - Revista de Ciências Sociais, Rio de Janeiro, Vol. 49, no-3, 2006, pp. 651 a 613. 


\section{Céli Regina Jardim Pinto}

flexão sobre a América Latina nas décadas de 1950 e 1960, como o promotor do desenvolvimento econômico e, posteriormente, como protagonista e garantidor do processo de redemocratização pelo qual passou a maioria dos países do subcontinente. Não vai longe o tempo em que os movimentos sociais ou qualquer outra manifestação da sociedade civil eram vistos como ocupantes, de certa forma ilegítimos, dos espaços deixados pelos partidos políticos, impedidos de funcionarem de forma plena durante o período da ditadura. Isto aconteceu em larga medida durante os anos de regime militar. No Brasil, um bom exemplo foram as comunidades de base promovidas pela Igreja Católica, que tiveram importante papel na politização de setores populares. Tais manifestações eram muitas vezes vistas como anomias no sistema político ou até como ameaças ao processo de redemocratização.

A entrada em cena da chamada sociedade civil no Brasil, de forma mais orgânica, aconteceu a partir das últimas décadas do século $X X$, como efeito de sua própria organização e pelos novos papéis a ela atribuídos, muito em decorrência do cenário político internacional, marcado pelo fim dos regimes comunistas do Leste europeu, pela crise do welfare state e pelo paralelo crescimento de políticas neoliberais ao redor do mundo.

A presença da sociedade civil no cenário político trouxe novos sujeitos para o espaço público, o que gerou um conjunto de imprecisões quanto a sua natureza. Arato e Cohen assim a definem: "enquadramento institucional do moderno mundo da vida estabilizado por direitos fundamentais, os quais incluirão no seu conjunto a esfera do público e do privado, desta vez do ponto de vista do mundo da vida" (Arato e Cohen, 1992:440, tradução da autora). Ela não é uniforme em sua constituição, pois é formada por grupos, instituições e pessoas com graus diferentes de organização, de comprometimento público e de capacidade de intervenção, para se relacionar com o Estado e com o mercado: pertence à sociedade civil um arco de entidades que abrangem desde clubes de mães até instituições globais como a Anistia Internacional.

O espaço da sociedade civil e suas funções, no que se poderia chamar de novo pacto, variam enormemente de autor para autor, desde os que o vêem como o contraponto virtuoso à corrupção e à letargia do Estado, até aqueles que lhe atribuem poderes quase revolucionários, como em uma espécie de nova vanguarda. Em meio aos extremos ficam aqueles que, vendo na sociedade civil potencialidades, apontam igual- 
mente para o perigo de sua supervalorização, que lhe atribui capacidades que não lhe são inerentes nem passíveis de serem adquiridas ${ }^{1}$.

O texto a seguir pretende examinar os limites, pontuar diferenças e levantar a problemática de um grupo de organizações da sociedade civil, as chamadas Organizações Não-Governamentais - $\mathrm{ONGs}^{2}$, no cenário brasileiro da virada do século, sendo seu objetivo principal examinar os espaços que estas organizações ocupam na relação com a sociedade e com o campo político. O primeiro problema a enfrentar é a imprecisão com que são usadas as noções de sociedade, sociedade civil, organizações da sociedade civil, movimentos sociais, ONGs. Estes vocábulos aparecem em textos acadêmicos, mas, principalmente, em pronunciamentos políticos em contraposição ao Estado, como se formassem um conjunto de entidades de natureza comum, que não necessitam ser definidas para que se entenda o tipo de posição e intervenção de cada uma delas, na própria sociedade civil, e a qualidade da relação que estabelecem com o Estado.

Para que se possa analisar propriamente a sociedade civil, faz-se necessária uma série de aclarações: uma medida inicial e salutar é afastar definitivamente a tentação de chamar de sociedade civil tudo aquilo que se diferencia de Estado e do mercado, e estar atento para não fazer distinção entre sociedade civil e sociedade civil organizada (o que nada tem a ver com organizações da sociedade civil). A sociedade civil é, em si, a forma de organização da própria sociedade, na qual cada indivíduo encontra sua pertença como cidadão de direito. O Brasil apresenta pelo menos uma grande peculiaridade em relação ao fenômeno, na medida em que convivem, no mesmo espaço, uma afluente sociedade civil e parcelas significativas da população, que dela está excluída.

A noção de exclusão, por sua própria natureza, é fluida, necessitando ser, não só constantemente definida e redefinida, mas também inserida em momentos e cenários históricos específicos. Não é uma noção que tenha um estatuto conceitual autônomo, sendo sempre relacional e definida a partir das condições concretas de indivíduos historicamente dados. Nesse particular, a noção diferencia-se completamente da classe: as classes estão definidas em ordens muito claras, os excluídos, não. Sua realidade não corresponde sequer à unidade do indivíduo, pois nenhum indivíduo está completamente excluído de todas as ordens de identificação. Portanto, poder-se-ia começar a delinear com mais clareza o excluído dizendo que todo excluído é incluído em alguma ordem, 


\section{Céli Regina Jardim Pinto}

familiar, religiosa, territorial, em grupos, bandos etc. Há inclusive situações em que indivíduos e/ou grupos são incluídos em uma ordem para poderem ser excluídos completamente de outra. Um caso paradigmático é o da mulher, que historicamente foi incluída na ordem privada para, com isto, ser excluída da ordem pública.

A complexidade e a pluralidade de situações de exclusão-inclusão, determinadas por embates políticos, tempos históricos e, mais recentemente, pelas lutas dos movimentos sociais não impedem, entretanto, que se identifiquem nas sociedades contemporâneas espaços bem demarcados de exclusão e de inclusão. Isto vale dizer que, tomando indivíduos e grupos nos mais diferentes cenários, há formas de exclusão que definem condições de desigualdade entre os cidadãos de um mesmo país regidos por leis que garantem a igualdade. Este é o caso de vastos contingentes de pessoas nos países latino-americanos na atualidade. Nesse contexto, a inclusão é fundamental na medida em que garante o pleno exercício de seus direitos de cidadãos. Os processos de inclusão podem ser estudados a partir do que se poderia chamar de dois momentos distintos da cidadania: o primeiro resume-se na máxima de Hannah Arendt do "direito a ter direitos"; o segundo refere-se ao exercício de fato desses direitos. A consciência de ter direito a direitos é uma condição necessária, mas não suficiente da cidadania, ou seja, é apenas um primeiro momento no processo de inclusão.

Em conseqüência, duas indagações se impõem: em um país com as condições do Brasil, qual é o espaço da sociedade civil na relação com o Estado? e qual a sua força no sentido de engendrar ações para aumentar seu próprio tamanho, diminuir a exclusão ou defender interesses de excluídos? No Brasil, a sociedade civil tem tido, historicamente, pouca ou nenhuma possibilidade de incorporar os excluídos, isto tem cabido primordialmente ao Estado, por meio de políticas públicas ou mesmo reformas, mais ou menos, radicais. Todavia, desde a Constituição de 1988 vem crescendo a presença da sociedade civil como ator político, quer por sua presença nos múltiplos conselhos que a própria Constituição determinou, quer pela sua organização, fazendo-se presente em inúmeras manifestações de cunho político, econômico ou cultural. Dentro desse quadro, a posição das ONGs tornou-se proeminente. Não há espaço neste artigo para discutir a história destas organizações e as inúmeras controvérsias sobre sua existência e atuação. O que interessa aqui particularmente é enfatizar que, no Brasil, temas como direitos humanos, meio ambiente e fome têm tido como porta-voz, em 
grande parte, um conjunto de ONGs, que toma a iniciativa diante do Estado, propondo políticas diretamente ao Poder Executivo ou pressionando o Congresso Nacional para aprovações de projetos de leis.

A hipótese que busco trabalhar neste artigo é a de que as ONGs têm sido elementos muito presentes na construção e na defesa do discurso dos interesses, tanto da sociedade civil, como da "não-sociedade civil". Em cenários como o brasileiro, onde há a concomitância de uma sociedade civil com formidáveis níveis de organização, com parcelas volumosas da população desprovidas de qualquer possibilidade de cidadania, estas organizações ocupam papéis de quase partidos políticos da sociedade. Essa hipótese deve ser entendida em um duplo sentido, em primeiro lugar, ao se aproximar as ONGs da noção de partido da sociedade civil, aponta-se para um conjunto de temas que não são necessariamente recortados pelos tradicionais partidos políticos e suas posições ideológicas, ou ainda não fazem parte dos tradicionais grandes temas da política brasileira. Qual partido representaria os direitos das mulheres, ou dos negros, ou das crianças? De uma forma ou de outra, todos os partidos falam destes temas, entretanto, o fazem através de suas óticas particulares e muito como resposta aos movimentos sociais e às pressões das próprias ONGs. O segundo sentido concerne aos novos cenários de participação na política dos distintos parlamentos, tais como conselhos, conferências, orçamentos participativos, nos quais as ONGs têm tido voz ativa como representantes de parcelas da sociedade civil ou como assessoras de movimentos sociais. Tais características não apontam para a crise dos partidos ou sua substituição no campo político, mas para novos espaços e temas surgidos nas últimas décadas, ocupados pelas ONGs. Isto ocorre em um momento delicado, pois sem nunca terem chegado a um amadurecimento estas organizações vivem uma constante crise, talvez causada por uma instabilidade própria de sua natureza.

As ONGs têm uma natureza instável, fruto tanto dos temas ao redor dos quais se organizam, quanto de sua instabilidade financeira, uma vez que sobrevivem por meio de projetos financiados por organizações internacionais, cooperação internacional entre países ou pelo próprio Estado. Atualmente, há uma diminuição de recursos internacionais para as ONGs, fazendo-as muitas vezes dependentes de recursos do Estado, o que provoca mudanças significativas na relação destas com a esfera oficial. Fernandes define ONGs a partir de suas características negativas: "não são governamentais, não são lucrativas, não fa- 
zem parte de estruturas maiores, não são representativas, não financiam" (Fernandes, 1994:25). Não sendo tudo isto, diferenciam-se claramente das demais instituições da sociedade civil, que são uma ou outra coisa. As ONGs, entretanto, têm outras características importantes, ainda no campo do "não": todas elas se apresentam como não-partidárias, mesmo assim, quer tomemos o Brasil como referência, quer tomemos as reuniões alternativas promovidas pelas ONGs nas grandes Conferências da Organização das Nações Unidas - ONU durante a década de 1990, não há dúvida sobre o caráter comprometido da grande maioria destas organizações com causas de justiça social, de fim da discriminação de qualquer natureza, de conservação ecológica, de direitos humanos. Em síntese, tanto as pequenas ONGs, muitas vezes ocupando-se de um problema muito localizado, como as grandes ONGs internacionais dividem a característica de serem organizações comprometidas com causas humanitárias que pretendem intervir para provocar mudanças nas condições de desigualdade e de exclusão ${ }^{3}$.

Muitas vezes as ONGs tendem a confundir-se com os movimentos sociais, mas contêm diferenças importantes que necessitam ser apontadas: 1) há um grande número de ONGs que surgiram a partir dos movimentos sociais, principalmente de movimentos identitários. O exemplo das ONGs feministas é certamente o melhor. Estas organizações representam um certo tipo de profissionalização da militância, e no caso do feminismo têm uma característica geracional muito forte: as ONGs da década de 1990, no Brasil, foram e estão sendo coordenadas em grande parte pelas militantes do movimento das décadas de 1970 e 1980. Também se encontra, atualmente, um número expressivo de organizações que tiveram origem no movimento negro e no movimento homossexual; 2) no que pese a característica anteriormente citada, as ONGs não substituem os movimentos nem são uma fase avançada destes, mas se relacionam com eles. Dividem com os movimentos sociais a fragmentação de seus temas, demandas e campanhas, mas seus funcionamentos são muito distintos: uma ONG só existe por intermédio de projetos que a sustentem, ela é pró-ativa, tem metas a cumprir, programas pré-estabelecidos e financiados. Os movimentos sociais são menos estruturados, não prestam contas, nem têm um grupo de profissionais para sustentar. As ONGs formalizam-se, possuem diretorias, conselhos e corpo de funcionários. Isto pode levar, pelo menos em tese, a um processo de auto-referência muito grande, no qual sua reprodução como organização tenha quase tanta centralidade como a causa que defende; 3) mesmo que muitas ONGs tenham se originado de movi- 
mentos sociais, esta não é a sua única origem, também surgiram de grupos de profissionais envolvidos com causas específicas, de ex-militantes políticos, tanto os que tiveram carreira interrompida pelo golpe militar, como os que se desiludiram e deixaram os partidos políticos por outras razões. As origens delimitam muito de perto a relação entre a ONG e a causa que defende.

As ONGs podem ser classificadas quanto a seus membros e às causas que defendem em dois grandes grupos: as organizações que defendem a causa de seus membros, formadas por negros contra o racismo, ou por mulheres contra o sexismo, ou por gays contra o preconceito em relação à escolha sexual; as que defendem a causa de outros, tais como meninos de rua, sem-teto, drogados, vítimas de abusos contra os direitos humanos, vítimas de abuso sexual, excluídos da cidadania por pobreza ou ignorância etc. Esta é uma característica fundamental destas organizações, pois é a partir das relações que estabelecem com o outro que podemos entender e analisar seu papel e suas funções nas relações sociedade civil-mundo da exclusão e sociedade civil-Estado.

As ONGs devem ainda ser consideradas em relação aos partidos políticos e à política institucional. Nas últimas décadas do século XX e nos primeiros anos do novo século, estas organizações têm tido posição de liderança no alargamento das questões políticas concernentes a direitos, em todos os sentidos, desde os direitos individuais até questões relacionadas com biodiversidade e direitos ecológicos. As ONGs foram centrais em campanhas públicas, em enfrentamentos diretos com o Estado e até em ações de desobediência civil na defesa de velhos e novos direitos. Decorre desta postura a incorporação, na agenda governamental, de temas que haviam ficado até então completamente ausentes da discussão pública e que, na maioria das vezes, não eram sequer reconhecidos como legítimos. Houve uma espécie de divisão do trabalho, cabendo aos partidos os temas tradicionais da política e às ONGs e às outras organizações da sociedade civil a publicização das novas questões, daí que é por meio da ocupação de espaços nas organizações da sociedade civil que os novos temas e atores puderam, muitas vezes, chegar ao espaço público.

O espaço ocupado pelas ONGs nas últimas décadas na arena pública foi sem dúvida importante e mudou em algumas áreas o patamar das discussões. Entretanto, isto não pode encobrir os inúmeros problemas que essas organizações, mesmo as mais poderosas e bem dotadas financeira- 
mente, enfrentam ou trazem com suas atuações, descontinuidade de programas e ações sociais, e limite de abrangência de programas.

\section{AS AÇÕES DOS NOVOS ATORES}

A presença das ONGs introduz uma série de novos elementos no campo da política, quer pela frágil institucionalização destas organizações, quer pela maneira diferenciada com que se relacionam com o campo, se comparadas com os atores tradicionais, tais como partidos políticos e autoridades governamentais. Não se trata aqui de fazer uma avaliação das vantagens ou desvantagens da presença das ONGs, tampouco de brindar esta presença como virtuosa em si. Analisar esta presença no espaço público objetiva avançar no conhecimento desse ator em três direções: verificar as formas como as ONGs se movem no campo; discutir as possibilidades e os limites da pretensão de representação das ONGs da sociedade civil diante do Estado; examinar as potencialidades das ações de empoderamento que pretendem engendrar ${ }^{4}$.

No que concerne às formas como as ONGs se movem no espaço público, vale chamar a atenção para o potencial de construção de redes, abrangendo os espaços locais, regionais e globais, como também as potencialidades de incluir nessas redes desde organizações internacionais, como as do sistema ONU e fundações financiadoras, até grupos semimarginalizados em bairros da periferia das grandes cidades. A noção de rede em relação às ONGs pode ser pensada de duas formas: uma é a rede entre ONGs incluindo também os movimentos sociais, na qual cada organização é ponto de transmissão para outras, maiores ou menores, locais ou globais. Outra forma de pensar a rede é como um espaço tridimensional onde as ONGs funcionam não apenas como pontos de transmissão, mas como pontos nodais, que acumulam e distribuem informações, acumulam poder, credenciam-se como representantes fazendo a ligação entre o Estado e a sociedade em geral ${ }^{5}$. É da capacidade de circular por todos esses pontos da rede que as ONGs tiram sua maior legitimidade e poder, construindo para si um status de representação muito particular.

Para avançar na compreensão da formação das redes, é necessário um exame das relações das ONGs entre $\mathrm{si}^{6}$. Se existe uma qualidade que não serve para identificar uma ONG é o seu tamanho. Sob o guardachuva da sigla encontram-se desde organizações de alcance mundial, cuja mais conhecida delas é o Green Peace, e, mais ultimamente, as 
organizações ligadas ao Fórum Social Mundial, como a $\mathrm{ATTAC}^{7}$, até pequenos grupos de seis pessoas organizadas em trabalhos comunitários, em bairros populares muito pobres. O importante é perceber as redes que se formam entre estes grupos, os fóruns e redes de ONGs, que tratam de um tema específico. Um exemplo claro deste tipo de dinâmica foi a reunião promovida com o então candidato à Presidência da República Luiz Inácio Lula da Silva pela Associação das ONGs do Brasil (ela própria uma importante $\mathrm{ONG}$ ), por ocasião da campanha eleitoral de 2002, para tratar do programa do candidato. Compareceram a esse evento: Articulação das Mulheres Brasileiras, Articulação de ONGs de Mulheres Negras, Articulação do Semi-Árido - ASA, Fórum Nacional de Assistência Social, Fórum Nacional de Mulheres Negras, Fórum Nacional de Participação Popular, Fórum Nacional da Reforma Urbana, Fórum ONGs/AIDS, Marcha Mundial das Mulheres, Plataforma de Direitos Humanos Econômicos, Sociais e Culturais Brasil, Rede de ONGs da Mata Atlântica, Rede GAPA e Rede Nacional Feminista de Saúde e Direitos Reprodutivos (disponível em www.abong.org.br, acessado em 13/3/2003).

Cada unidade anteriormente citada representa um conjunto de organizações, pois são todos fóruns ou articulações, dando uma idéia quase pictórica da constituição de uma rede. A existência da rede não impede, todavia, que se indague sobre a possibilidade do estabelecimento de estruturas piramidais e hierárquicas. Se os fóruns e as articulações discutiram em suas bases as propostas que trouxeram para a grande reunião, estar-se-ia diante de um exemplo de alastramento de participação; o problema, entretanto, encontra-se na situação inversa, isto é, na possibilidade de os representantes dos fóruns e articulações estarem muito mais ligados entre si do que a suas bases ${ }^{8}$. De qualquer forma, tais redes podem ser ou vir a ser espaços de participação mais representativos da sociedade civil, tanto pelo número de pessoas que delas tomam parte, como pelos eventos e embates com o campo político que propiciam.

Os exemplos mais comuns de redes de ONGs são entre organizações que se ocupam do mesmo tema e entre organizações que estabelecem parcerias e assessorias, envolvendo, em qualquer dos casos, redes de ONGs nacionais e redes de ONGs brasileiras e estrangeiras. Dois exemplos são ilustrativos: o primeiro é o da SOF, que segundo seu site estava filiada em 2003 à Rede Nacional Feminista de Saúde e Direitos Reprodutivos, à Rede Mundial de Mulheres pelos Direitos Reproduti- 
vos e à Associação Brasileira de ONGs - ABONG (disponível em www.sof.org.br, acessado em 25/5/2003). Interessante notar aqui a existência de três redes, a nacional pelos direitos reprodutivos; a internacional, também pelos direitos reprodutivos; e a de ONGs ligadas a direitos humanos, democratização e justiça social, que é como se autoqualifica a ABONG. Outro exemplo significativo é o do CEPIA que, em 1997, em parceria com o Center for Health \& Social Policy, uma ONG norte-americana, fundou o Fórum da Sociedade Civil nas Américas. Deste fórum constam, segundo informações do CEPIA, 26 lideranças de ONGs de 13 países do continente (disponível em www.cepia.org. br, acessado em 10/3/2004). Uma terceira forma de rede foi a construída pelo CELIM, que, com sede no Rio de Janeiro, criou núcleos de replicação de seus cursos de liderança em diversos estados do país, tão distantes como o Ceará, Santa Catarina e Rio Grande do Sul (disponível em www.celim.org.br, acessado em 13/3/2003).

A noção de redes e fóruns de ONGs permite visualizar o campo de alcance destas organizações e pode explicar sua grande presença nos espaços públicos da sociedade civil. As ONGs têm dois eixos de atuação importantes, um na direção das populações excluídas, isto é, na direção da sociedade não-organizada, outro, na direção do Estado. Neste momento é fundamental relembrar a distinção entre essas organizações e os movimentos sociais, pois parece estar nessa diferenciação a especificidade de seu papel e a própria importância que tomou como interlocutora junto a governos, independentemente da coloração partidária e ideológica destes. Em relação a esses dois eixos, as ONGs podem funcionar como correia de transmissão ou não, isto é, podem ir até os excluídos para aproximá-los do Estado, ou podem ir até os excluídos com fins de executar políticas de saúde, prevenção, empoderamento e advocacy.

Nessa aproximação, as ONGs fazem muitas vezes parcerias com movimentos sociais, para criar grupos de pressão contra o governo. Atualmente, muitos movimentos sociais expressam-se por ONGs, outros apenas relacionam-se com elas, e estas, por sua vez, podem existir completamente independentes dos movimentos. Na relação direta com a sociedade, as ONGs desenvolvem primordialmente projetos de empoderamento, que são na maioria das vezes de dois tipos: projetos que se dirigem a populações excluídas e em risco de marginalização, com o intuito de fortalecer a auto-imagem e promover qualificação profissional através de cursos, atividades artísticas e seminários, os úl- 
timos com o objetivo de discutir as condições de vida destas populações. Uma segunda forma de intervenção é a de treinamento de lideranças dentro ou fora dos movimentos sociais para a defesa de interesses das comunidades. A ONG CELIM, do Rio de Janeiro, já citada como exemplo, desenvolveu um projeto (ativo em 2003) que apresentou uma série de características próprias do primeiro tipo de intervenção. $\mathrm{O}$ projeto que leva o nome de "Ser Menina" é assim descrito:

"Ser Menina é um projeto realizado na Zona Oeste do município do Rio de Janeiro. Trabalha com meninas adolescentes de comunidades de baixa renda, de 12 a 18 anos. Ao longo de dez anos, vem desenvolvendo ações educativas de resgate da identidade e auto-estima, voltadas para a arte, cultura, saúde e profissionalização. O objetivo é o de fortalecer as competências de cada menina, dando-lhe a possibilidade de ampliar seus horizontes e perspectivas de futuro. São atendidas 60 meninas, em horário complementar à escola, utilizando-se a rede de serviços local para fortalecimento do trabalho com elas e suas famílias. [...], em parceria com a Fundação Abrinq, formando mediadoras em leitura, estimulando o trabalho voluntário em creches, asilos e escolas e atuando com a Rede Jovem que, através do Espaço Jovem, possibilita acesso grátis à internet, objetivando a interlocução com outros jovens do Brasil" (disponível em www.celim.org.br, acessado em 15/3/2003).

Esse é um projeto típico de intervenção das ONGs nas comunidades carentes e excluídas de quase todos os benefícios e direitos, por meio de um trabalho de empoderamento. Três aspectos são particularmente importantes: o primeiro é o próprio objetivo central do projeto, criar auto-estima em adolescentes do sexo feminino, preparando-as para a integração no mundo competitivo, aproveitando a rede local; a segunda característica é a parceria com uma grande fundação, no caso a Abrinq, que muito provavelmente financiou o projeto'; o terceiro é o efeito cascata que muitos desses projetos propõem, isto é, o treinamento de pessoas para serem mediadoras na comunidade através de trabalho voluntário. Observa-se aqui uma ONG de mulheres intelectualizadas coordenando um projeto "Ser Menina", que por sua vez deu base a um outro projeto, "Mudando a História", e que se liga a uma rede, "Rede Jovem", chegando à internet.

O segundo tipo de intervenção é o de treinamento de lideranças, do qual é um bom exemplo o "Programa Direitos da Mulher na Lei e na Vida", que tem sido coordenado pelo CEPIA no Brasil e que é parte de um programa maior atingindo vários países da América Latina. O Pro- 


\section{Céli Regina Jardim Pinto}

grama foi levado a efeito em parceria com três outras ONGs latino-americanas e financiado pela Fundação Ford. Seu objetivo, segundo seus coordenadores, era

"[..] propiciar um espaço de formação e treinamento em estratégias e habilidades de advocacy, de reflexão e aprofundamento teórico, de sistematização de informações e de troca de experiências para cerca de 230 ativistas feministas latino-americanas e suas organizações. [...] Esse trabalho tem por objetivo fortalecer as organizações de mulheres para influir no debate público e nas agendas políticas a partir da perspectiva feminista, e para conceber e desenvolver políticas públicas que contemplem as demandas das mulheres e atendam às resoluções das Conferências de Cairo e Beijing*, em especial na área de saúde e direitos sexuais e reprodutivos" (disponível em www.cepia.org.br, acessado em 22/4/2003).

Trata-se, pois, de um projeto internacional de grande envergadura que aconteceu no estrito limite da sociedade civil, ou seja, não se dirigiu às parcelas dos chamados excluídos. O propósito não foi empoderar mulheres pobres e excluídas de bairros populares, mas dar instrumentos para as mulheres que já exerciam lideranças para que estas tivessem como pressionar seus governos para a implementação de políticas públicas relacionadas com as decisões da Conferência de Beijing de 1995. Em decorrência dessas ações, políticas públicas implementadas podem provocar ações concretas de inclusão, mas isto é um efeito não-controlável e indireto. Nesse tipo de atuação, a ONG mãe (aquela que gera o programa) pode se dirigir a outras ONGs menores, ou a representantes de movimentos sociais. Desta forma, a relação das ONGs com o movimento social é sempre no sentido profissional de dar instrumentos ao movimento. A interferência da organização tem sempre um componente técnico, muitas vezes um saber específico, atestado pela qualificação de seus membros, o que permite criar um distanciamento do caráter mais imediatista, militante e muitas vezes ideológico do movimento social. Isto ocorre com muitas ONGs que tratam com questões de gênero ou de mulheres negras: as integrantes destas organizações se reconhecem como integrantes do movimento social, mas ao mesmo tempo colocam-se fora dele, em uma posição que poderia ser vista como de promotoras ou de vanguarda intelectual dos mesmos.

\footnotetext{
* Transcrição pinyin para Pequim. (N. do E.)
} 
As relações entre as ONGs e o Estado são também complexas e variadas, duas delas são particularmente significativas: de treinamento da burocracia estatal e de assessoria parlamentar. A primeira diz respeito a convênios entre ONGs e órgãos do Estado para treinar a burocracia nos temas dos direitos dos cidadãos, principalmente no que concerne aos direitos das mulheres. Existe um bom número de experiências desse tipo no Brasil, e elas são importantes porque se trata de, indiretamente, ligar duas pontas muito distantes uma da outra: o aparato estatal e as frações menos organizadas e excluídas da sociedade.

A AGENDE, em parceria com um Núcleo de Estudos e Pesquisas sobre a Mulher da Universidade de Brasília executou um projeto de grande alcance, "A Resolução Institucional dos Conflitos: acesso aos direitos humanos das mulheres no Brasil". Os objetivos do projeto permitem perceber um quadro bastante esclarecedor de seu alcance:

\begin{abstract}
“Tem por objetivo contribuir para a erradicação das múltiplas formas de discriminação nos principais âmbitos governamentais encarregados de administrar conflitos interpessoais e tratar das pessoas violentadas nesses conflitos. Focaliza-se nas práticas de discriminação de classe, gênero, cor, geração, opção sexual, origem regional, envolvendo, inclusive, discriminações baseadas na estética que incidem sobre a aparência, trajes e linguagens. As práticas de discriminação enfatizadas na pesquisa e que se pretende erradicar nas atuações governamentais são as que incidem, sobretudo, contra as mulheres e os não brancos" (disponível em www.agende.org.br, acessado em 14/5/2003).
\end{abstract}

O projeto é particularmente ilustrativo de um tipo de trabalho de linha de transmissão que as ONGs realizam, pois se destina às instituições públicas que tratam com as mulheres nas áreas de segurança pública, saúde e trabalho, portanto, a ONG está agindo diretamente no âmbito governamental, buscando garantir, segundo seus objetivos explícitos, serviços que sejam adequados às usuárias. Neste projeto, a ONG é um elo entre o agente estatal, que está sendo treinado, e as mulheres usuárias desses serviços ${ }^{10}$.

Em uma linha bastante próxima, o CEPIA desenvolveu em 2001 um programa de capacitação de funcionários da área de segurança pública cujo tema era os direitos das mulheres: "Nesse projeto a equipe da CEPIA acompanhou, em 2001, cinco Seminários promovidos pela Secretaria dos Direitos das Mulheres - SEDIM, nas cidades de Brasília, São Paulo, Rio de Janeiro, Recife e Vitória, voltados para apresentação 


\section{Céli Regina Jardim Pinto}

da pesquisa realizada por esse órgão sobre as 305 Delegacias de $\mathrm{Mu}$ lheres de todo o país" (disponível em www.cepia.org.br, acessado em $22 / 11 / 2003$ ).

Esses projetos de sensibilização dos servidores públicos são realizados a partir de uma posição de pouco poder, tendo muitas vezes enfrentado resistências, ao contrário do que ocorre quando as ONGs têm assento em conselhos ou em trabalhos de empoderamento de populações excluídas, onde a presença das organizações é percebida, muitas vezes, como um ganho. Em projetos dirigidos à burocracia estatal, há um trabalho de conquista que envolve o rompimento de rotina e até de interesses corporativos.

O comprometimento como uma causa que não lhe é própria, associada à autoridade dada pelo profissionalismo e o posicionamento apartidário, parece ser o caldo de cultura que possibilita a estas organizações um tipo muito específico de intervenção no aparato estatal. Estas mesmas características habilitam as ONGs para outros tipos de intervenção no cenário da política institucional, como o acompanhamento do legislativo feito pela ONG CFEMEA, por muitos anos em Brasília:

\footnotetext{
"Monitoramento das proposições no Legislativo Federal e sensibilização das parlamentares e assessores / as legislativos objetivando a incorporação de uma perspectiva de gênero na elaboração da legislação. Abrange, também, a defesa da implementação de políticas públicas que contemplem a cidadania das mulheres, mediante a alocação de recursos no Orçamento da União e a fiscalização de Atos do Poder Executivo [...]. Esse trabalho é realizado em estreita parceria com a Bancada Feminina de parlamentares e junto às Comissões Permanentes e Temporárias da Câmara dos Deputados e do Senado Federal" (disponível em www.cfemea.org.br, acessado em 14/3/2003).
}

No caso específico desse trabalho, a ONG não está nem ocupando cargo de representação, como seria uma posição em um conselho, nem fazendo ponte entre setores da sociedade organizada ou não com o Legislativo, mas atuando como uma instituição com competência técnica que, por meio de projetos específicos, mantém um corpo de profissionais para acompanhar e pressionar deputados, senadores e partidos na direção da aprovação e implementação de políticas públicas de interesse das mulheres. 
Antes de introduzir o último exemplo de ação de ONGs cabe, pela natureza desta intervenção, uma breve digressão sobre a posição das ONGs diante da política partidária e eleitoral stricto sensu. Trata-se de uma reunião nacional para fazer uma plataforma feminista para os candidatos às eleições de 2002. Essas organizações tomam para si, algumas vezes, tarefas tradicionalmente atribuídas aos partidos políticos, como a luta por direitos e apresentação de projetos nos legislativos. Também participam no campo da política de inúmeras outras formas, algumas das quais foram comentadas neste artigo. Nenhuma dessas ações, entretanto, atua no sentido de formar quadros para a arena política dando instrumentos aos setores excluídos ou mesmo militantes de movimentos sociais para chegarem até os partidos e disputarem cargos eletivos.

A Conferência Nacional de Mulheres Brasileiras ocorrida em Brasília, nos dias 6 e 7 de junho de 2002, foi organizada com o objetivo de definir uma plataforma política feminista para as eleições gerais de outubro de 2002 e promovida por 10 organizações, sendo que apenas duas não eram ONGs: a Central Única dos Trabalhadores - CUT e a Secretaria Nacional de Mulheres do Partido Socialista Brasileiro ${ }^{11}$.

A Conferência reuniu 1.408 inscritos, dos quais 99\% eram mulheres, em sua grande maioria com mais de 30 anos (+ de 70\%), sendo que a maior parte encontrava-se na faixa dos $41-50$ anos $(29,69 \%)$, e uma grande porcentagem (41\%) declarou-se afro-descendente. Não existem informações sobre a renda pessoal ou familiar, mas o grau de escolaridade é um dado bastante relevante e permite algumas inferências: $5 \%$ das mulheres eram pós-graduadas; $34,87 \%$ tinham nível superior; $33,45 \%$ tinham o nível médio. Mais de $70 \%$ das mulheres presentes na Conferência, portanto, tinham um elevado grau de instrução em relação à população brasileira. Perguntadas sobre sua atuação política, $32,19 \%$ pertencem a ONGs; $34,70 \%$ a movimentos sociais; $20,21 \%$ a partidos políticos; $7,53 \%$ a órgãos governamentais e $5,37 \%$ a universidades. Um dado significativo na pesquisa que foi feita é que $39,35 \%$ das participantes declararam-se chefes de família. No grupo, o que chama a atenção particularmente é o alto comparecimento de mulheres que se auto-identificam como afro-descendentes, o que revela a existência de uma organização bastante importante no grupo. Estes dados são eloqüentes no que concerne à existência de uma sociedade civil ativa no país, ao mesmo tempo em que os dados referentes à educação revelam que este é um espaço bastante diferenciado no universo 
educacional brasileiro ${ }^{12}$ (disponível em www.cepia.org.br, acessado em abril de 2003).

Os projetos examinados nas páginas anteriores indicam que as ONGs estão buscando construir novos espaços de discussão pública, de luta por direitos e cidadania para as camadas menos organizadas do país, portanto, poder-se-ia afirmar que as ONGs têm potencial para ser um dos instrumentos importantes no fortalecimento da sociedade civil. Estas organizações constituem redes das mais diversas formas no interior da sociedade civil, que podem abranger somente ONGs, como também organismos internacionais, movimentos sociais, entidades filantrópicas. As ONGs também se tornam, em alguns momentos, parceiras do Estado, na discussão, proposição e até implementação de políticas públicas. Cabe, diante deste intenso movimento, perguntar quais as conseqüências da presença desse novo ator.

No que concerne ao Estado, a presença das ONGs provoca pelo menos dois efeitos importantes: o primeiro concretiza-se na tendência de o Estado ver estas organizações como sinônimo de sociedade civil, buscando desta forma solucionar a difícil tarefa de administrar a representação da sociedade civil em órgãos estatais; o segundo efeito refere-se ao fato de as ONGs aparecerem como parceiras do Estado em projetos sociais ou em projetos de capacitação de servidores públicos. Em qualquer um dos dois efeitos pode-se observar a posição de vanguarda em que estas organizações se colocaram (e que realmente tiveram em muitos casos) e ao mesmo tempo o problema que aparece na relação que estabelecem com o Estado quando o último as considera sinônimo de sociedade civil.

Outra conseqüência da presença das ONGs é seu papel de interlocutor de setores da sociedade civil: a independência financeira somada à independência partidária ideológica destas organizações fazem delas potenciais "partidos" da sociedade civil, pois dividem com ela a fragmentação e a transversalidade de seus interesses e suas demandas, como foi visto nos exemplos de organização de plataformas para candidatos.

Ainda sobre a presença das ONGs nos espaços públicos e no campo específico da política cabe chamar a atenção para a impossibilidade, pela própria natureza destas organizações, de tomarem para si as responsabilidades referentes à educação, à saúde, entre outras questões de responsabilidade do Estado. Os exemplos comentados ao longo deste ar- 
tigo apontam para a potencialidade do limite das ações. As ONGs têm sido sem dúvida importantes atores na sociedade e no campo político nos últimos 20 anos e, possivelmente, continuarão a ocupar espaços, os aqui descritos e novos. Tem cabido a elas a responsabilidade de formidáveis mobilizações por direitos, formações de rede e programas de empoderamento. Elas também têm sido, em grande medida, responsáveis pela presença no campo político de temas que historicamente encontraram resistência no interior dos partidos políticos, entre os quais se destacam os temas dos direitos das mulheres. Entretanto, estas organizações não podem ser vistas de maneira simplista, como substitutas de partidos políticos, do Estado ou mesmo dos movimentos sociais. Suas ações têm limites, entre eles o fato de serem fragmentadas, atingirem o conjunto da sociedade de forma limitada e dependerem de financiamentos pontuais.

(Recebido para publicação em outubro de 2005)

(Versão definitiva em agosto de 2006)

\section{NOTAS}

1. Especialmente importantes dentro de uma perspectiva que analisa criticamente a sociedade civil, chamando a atenção para suas potencialidades de luta pela cidadania, mas também para suas fragilidades em substituir o Estado estão dois livros basilares: Young (2000) e Chandhoke (2003).

2. As informações constantes deste artigo sobre as ONGs foram retiradas das páginas de internet de cada uma delas entre os anos de 2002-05, período em que se estendeu pesquisa sobre o tema sob minha coordenação. Como o interesse primordial é perceber como estas organizações se concebem e se apresentam ao público, esta fonte foi de especial importância.

3. A proliferação de ONGs no mundo contemporâneo, e mesmo considerando somente o Brasil, é de tal monta que se torna muito difícil construir uma caracterização geral. Parece bastante possível que se possam encontrar organizações com características muito diferentes das que foram listadas, pode haver inclusive organizações não-governamentais que estejam encobrindo atividades do mercado ou até mesmo atividades ilícitas, isto, contudo, não parece quantitativamente relevante a ponto de descaracterizar o conjunto destas organizações.

4. O conceito de empoderamento refere-se à ação de dotar indivíduos de instrumental que os torne capazes de lutar por seus direitos e exercer sua cidadania. 


\section{Céli Regina Jardim Pinto}

5. Neste artigo não será tratada a presença das ONGs nos conselhos municipais, estaduais e nacionais, nos quais esta tem sido destacada (Gohn, 2000; Rachelis, 2000; Santos, 2000). O objetivo do texto é examinar a relação das ONGs com o Estado e não sua presença no aparato diretamente.

6. A partir deste momento, valer-me-ei de um conjunto de ONGs que tratam da questão de gênero no Brasil como exemplo para o argumento que estou desenvolvendo, são elas: AGENDE (Ações em Gênero, Cidadania e Desenvolvimento); CFEMEA (Centro Feminista de Estudos e Assessoria); CEPIA (Cidadania, Estudo, Pesquisa, Informação e Ação); SOF (Sempreviva Organização Feminista); CELIM (Centro de Liderança da Mulher). Foram três os critérios de escolha das ONGs: o primeiro e mais óbvio, todas as organizações tratam da questão dos direitos da mulher, objeto central da pesquisa da qual este artigo é um dos resultados; o segundo critério é de importância, e todas são ONGs com alcance nacional, no que pese na maioria das vezes estarem em São Paulo ou Rio de Janeiro e com projetos importantes no campo dos direitos e de políticas sociais; em terceiro lugar, a amplitude de suas atividades, que nos permite exemplificar toda a rede construída pelas ONGs e assim responder com acuidade as questões propostas.

7. A ATTAC (Ação pela Tributação das Transações Financeiras em Apoio aos Cidadãos), com contatos em 38 países, define-se desde sua criação como um "Movimento Internacional para o controle democrático do mercado financeiro, e sua instituição quer responder esta demanda. Constitui-se em uma rede sem estruturas hierárquicas nem centro geográfico, com a plataforma adjunta como referência. É pluralista, se enriquece com a diversidade de seus componentes e favorece a ação comum sem limitar de nenhuma maneira a liberdade de intervenção de cada um. Propõe-se a reforçar, relacionar e coordenar no âmbito internacional a intervenção de todos os associados que se reconhecem em sua plataforma com todas as outras redes cujos objetivos convergem com os seus" (disponível em www.attac.org, acessado em 20/4/2003, tradução da autora).

8. O controle sobre este tipo de atividade é de difícil aferimento, envolvendo questões metodológicas sofisticadas e pesquisa de grande extensão.

9. A Fundação Abrinq pelos Direitos da Criança e do Adolescente é uma entidade sem fins lucrativos, de Utilidade Pública Federal, que tem como objetivo promover os direitos elementares de cidadania das crianças. Afirma-se que muito provavelmente financiou o projeto devido à dificuldade à época da pesquisa que gerou este artigo de se obter informações sobre o financiamento das ONGs.

10. Cabe, mais uma vez, a observação que este artigo não se propõe a fazer uma avaliação do trabalho das ONGs, mas traçar um quadro amplo das redes e interlocuções destas organizações. Neste caso particular, como nos outros casos descritos, não foram investigados os outputs das ações das ONGs.

11. As demais organizações foram: Articulação de Mulheres Brasileiras; Articulação Nacional de Mulheres Trabalhadoras Rurais; Articulação de Mulheres Negras Brasileiras; Secretaria para Assuntos da Mulher Trabalhadora da Confederação Nacional dos Trabalhadores em Estabelecimentos de Ensino - CONTEE; CEMINA; Rede Nacional de Parteiras Tradicionais; RedeSaúde; União Brasileira de Mulheres.

12. A sociedade civil é o espaço, por excelência, dos incluídos, isto é, daqueles que possuem não só a consciência dos direitos, mas que lutam para conquistá-los. Neste sen- 
tido, os dados para o ano de 2000 referentes ao Brasil são eloqüentes: “Todos os estudos e estimativas deduzem que a sociedade brasileira organizada não representa mais de $15 \%$ da população do país. Ou seja, $85 \%$ da população brasileira é sociedade desorganizada [...]. Na Europa, por exemplo, $80 \%$ ou mais da população está ligada a alguma forma de organização" (Teixeira, 2000:20).

\section{REFERÊNCIAS BIBLIOGRÁFICAS}

ARATO, Andrew e COHEN, Jean. (1994), Civil Society and Political Theory. Cambridge, MIT Press.

CHANDHOKE, Neera. (2003), The Conceits of Civil Society. Oxford, Oxford University Press.

FERNANDES, Rubem César. (1994), Privado, porém Público - o Terceiro Setor na América Latina. Rio de Janeiro, Relume Dumará.

GOHN, Maria da Glória. (2000), “Os Conselhos de Educação e a Reforma do Estado”. Pólis, no 37 .

RACHELIS, Raquel. (2000), “Sistematização: Os Conselhos de Gestão no Contexto Internacional”. Pólis, no 37 .

SANTOS, Nelson Rodrigues, (2000), "Implantação e Funcionamento dos Conselhos de Saúde no Brasil". Pólis, no 37.

TEIXEIRA, Elenaldo. (2000), “Sistematização: Efetividade e Eficácia dos Conselhos". Pólis, no 37 .

YOUNG, Iris. (2000), Inclusion and Democracy. Oxford, Oxford University Press. 


\section{Céli Regina Jardim Pinto}

\section{ABSTRACT}

NGOs and Politics in Brazil: The Presence of New Actors

This article's main objective is to analyze the spaces occupied by nongovernmental organizations (NGOs) in Brazilian politics. The first section seeks a clear definition of the main characteristics of these organizations, especially concerning their relations to social movements. The second part analyzes a set of actions by Brazilian NGOs, most of which originating from the women's movement, in order to exemplify their range of action in relation to the state and civil society as a whole, particularly as regards issues of citizens' rights.

Key words: civil society; political participation; NGO

\section{RÉSUMÉ}

Les ONG et la Politique au Brésil: Présence de Nouveaux Acteurs

Dans cet article, on analyse les espaces occupés par les ONG dans la politique brésilienne. Il se compose de deux parties: dans la première, on cherche à définir les caractéristiques fondamentales de ces organisations, surtout leurs particularités par rapport aux mouvements sociaux. Dans la seconde, on analyse un ensemble d'actions d'ONG brésiliennes, issues du mouvement féministe pour la plupart, dans le but d'illustrer le type d'actions qu'elles mènent vis à vis de l'État et de la société civile dans son ensemble, surtout en ce qui concerne les questions de droit et de citoyenneté.

Mots-clé: société civile; participation politique; ONG 